\title{
DESIGNING AND IMPLEMENTING OF AN ONLINE LIBRARY MANAGMENT SYSTEM
}

\author{
Maiwan B. Abdulrazzaq*, Omar Mohammed Mustafa \\ Dept. of Computer Science, Faculty of Science, University of Zakho, Kurdistan Region - Iraq. \\ maiwan.abdulrazzaq@uoz.edu.krd
}

Received: Jun. 2017 / Accepted: Aug., 2017 / Published: Sept., 2017

https://doi.org/10.25271/2017.5.3.396

\begin{abstract}
:
One of the most important fields in education is library. The library is a fast-growing system. The traditional methods of maintaining it are no longer dynamic and efficient. For expeditious retrieval and dissemination of information and better service for the clientele, an application of modern techniques has become absolutely indispensable. A properly computerized library will help its users with quick and prompt services. Therefore, this Paper produces an efficient Online Library Management System (OLMS) for university campus. The main purpose of this Paper is to design and implement the (OLMS). The OLMS consists of two modules: External Pages Module and Internal Pages Module. The first module is with limited operation such as (viewing, searching and registration request). The second module for the personal account can do the operations like (storing, searching, viewing, borrowing, downloading and etc.). The system controllers are two types. The first one is the (Co_Admin) which can manage library operation. The second one is the administrator which can create and manage university libraries and also can create (Co_Admin) for each faculty library. The system can generate different types of reports and can also calculate the (fines) on the users, also any request or response will be done by E-Mail and short message service (SMS). The OLMS was designed and implemented by using (MySQL, HTML, CSS, PHP, JavaScript, JQuery, Ajax and Bootstrap) techniques. The system was tested in two phases: the first phase identifies the views and preferences of users with the specification of the system outputs, depending on the requirements of the proposed system. The second phase measures the abilities of the system through System Usability Scale (SUS) technique with the contribution of 26 potential users of the system and the recorded rate $76 \%$ as overall satisfaction of OLMS implementation. A reasonable degree of compatibility and harmony between the university and the system requirements of application has been found in the University of Zakho.
\end{abstract}

KEYWORDS: Online Library Management System, E-Library Search System, Digital Library Management System, PHP, MYSQL.

\section{INTRODUCTION}

People and organizations use information every day. Information system (IS) is a collection of solid components that gather, operate, save, upload data, information and grant feedback technique to achieve an objective. Those feeding techniques enable organizations and managers to reach out their goals. The information technology covers the applications of computer based systems dealing with organization, storing, searching, restoring and illustrating. Information technology programs and the methods are used by the library managers for processing the information, communication among its users and deployment of the latest changes. Recently, digital libraries have been re-implemented using information Technologies. The traditional method of managing a library is not efficient anymore in current world in which the library is growing rapidly. The computerized service of library will let users have reliable and accurate services. Library mechanization leads to automation of library tidying operations mainly by computerization. The most frequently known organization operations are gaining control, serials switch, classification, and cataloging (Neelakandan, Duraisekar, Balasubramani, \& Ragavan, 2010). In most universities of Kurdistan region, the utilization of the information technology is still limited as in Zakho University, which is supported by the interviews that was conducted by the researcher. The problem of the study lies in the lack of electronic system to manage the operations in all Universities libraries in the region. Depending on the interview and observation, the current system is incapable of adapting the Universities necessities for gaining important information on time. This is usually the result of lack of combination and cooperation for such system sections. Therefore, the current system used by the researcher is quite significant to be applied in Universities setting.

\section{RELATED WORKS}

Number of related works and researches has been referenced. (Morium, 2008), says that the library system of their country is in poor conditions. The researcher then mentions Brac University Aysha Abed Library system as an example. The lack of as acquisition, circulation and reporting are the main problem of mentioned library system. Therefore, lacking a standard system will cause problems to create a usable network among all libraries. This author argues that a shared database system would aid transferring from the previous system to a new one. The need of a complete modern library system is completely clear, which should be cheap and efficient, Morium says. The developer believes an open source library system is proposed solution to their problem. According to the author argues, these services should be free for use and available to public. (Al-Juboori, 2014), proposed to design and present ELibrary Search System (ELSS) for University of Kerbala. Elibrary system makes the work of a person who is in charge of the library more convenient to search, arrange and make an inventory of the contents of the library. In that paper, a search system for an E-Library for the academic organizations was

\footnotetext{
* Corresponding author

This is an open access under a CC BY-NC-SA 4.0 license (https://creativecommons.org/licenses/by-nc-sa/4.0/)
} 
introduced such as universities, researches centers. The proposed system has some methods of searches and it is convenient for the researchers to find their required information. The system data base contains two categories, Books and Theses. The administrator of the E-Library can add, update, and delete any information in the database easily. He developed an E-Library Search System using PHP, MYSQL and APACHE with WAMP server. (Chiagunye \& Nwachukwu, 2015), Designed a Web Based Digital Library Management System (DLMS) for Institutions and Colleges. The researcher aimed to make the organization library available to students or clients at a click of mouse in respective areas of choice. It enables students to have access to latest learning facilities such as, articles, journals, textbooks, thesis, projects, newspapers, etc. with their computer systems without going through the severe steps and routine in the conventional organization libraries. In general, this project has worked on easing the usage of an online library system. There have been challenges and problems covering in this project. These difficulties have been tackled in this project and have been described. (Aruleba, Akomolafe, \& Afeni, 2016), the researcher develop and implement an IR system that minimizes the hurdles related with current system of searching in Libraries. It is displayed in the system that users looking full text high probably find relevant articles than searching only the abstracts. The result confirms the price of full text collections for text retrieval and provides a framework for bring into line searching algorithms that take advantage of sharply developed digital archives. In addition, there are a number of aspects that could be developed. For instance, increase the volume of the database: this would enable huge data storage. What's more, integrating advert plans for research materials: the organization would be willing to sell online. Additionally, acquiring and publishing video, audio and large graphic research materials. Moreover, developer used a professional way to search of text without taking in mind the SWOT analysis and in addition the system does not provide online registration for users. The current system is distinguished from the traditional system through some features like the current system, as part of a comprehensive project for automating administrative work within the campus. On that basis, the proposed system differs from all the previous works through SWOT analyses the internals factor within three universities (UoZ, UoD, and NU). As well as, this work includes implementation of the proposed system in Zakho university campus. Also, the system will contain the operations of online (borrowing books, fines, reborrowing). The paper is organized in the following way.

\section{RESEARCH METHOD}

Collecting data and information need from the researcher should be aware of internal and external concepts and influences on that system along with the static data of frequent incidents. The answering of research would not be enough if the researcher or developer does not take into consideration the positive and negative hypothetic. Also, the methods of research should be clear and promising. The methods should be described in full detail for the study to be simulated, or at least repeated in a similar way in other situations. All stages have to be explained and acceptable with clear motives for the choice of researcher's particular methods and materials. There are a number of ways to achieve an answer to the type of method that has to be chosen, but the method has to be selected wisely (David, 2012).

The researchers used in this system more than one style to gather and obtain the requirements. These styles are:

\subsection{Quantitative Method}

The method of quantitative research is based on how a set of factors are forming a research method. The study relies on a number of factors, acts and reactions performing internally and externally around the research. If a practical approach to research methods is taken, firstly it should be clear what types of questions are best answered using quantitative as contrast to qualitative methods (David, 2012). This study used such method in System Usability Scale (SUS) technique.

\subsection{Qualitative Method}

Qualitative is the study of quality factors of a research, which depends on the accuracy of the data rather than the size of data. Qualitative method is a term which is used for research purposes in a number of specific cases that help the researcher to obtain some realistic results (Jo, 2011). This study used such method in the interview, observation and SWOT analysis.

\subsection{Interview}

Interviews are extensive tools to get public's involvements and their base perceptions, attitudes, and feelings of reality. Organized interviews could be grouped into three different types, structured interviews, semi-structured interviews, and interviews that have a range of predefined questions. This generalization is envisioned to decrease the effects of the tool and the interviewer on the research outcome. Structured interviews are similar to surveys, but they are managed verbally rather than in writing. Semi-structured interviews are more flexible (McCann \& Clark, 2005). This researcher used the interview method to get the data and determine the requirements of the proposed system during the period of $(1 / 12 / 2014$ to $1 / 4 / 2015)$.

\subsection{Observation}

Gathering data is concluded in interview and observation system. Those methods are applied for a specific type of research which is counted as a way of researching. Observation could be done on almost every type of research depending on how the question of the research is (Joonas, 2013).

In this system, the observation is conducted by this researcher at the period (4/1/2015-1/4/2015) to get and determine the requirements of the system design as a registration form, borrowing form, searching box, administrative order, and some of traditional system.

\subsection{SWOT Analysis}

The SWOT analysis has been done through interviews and observations with three universities (UoZ, UoD, and NU) in Kurdistan region. During the interviews schema was used for the current system and our proposed system. The observation was done by monitoring a number of documents which were used to run their paper-based system. Their functioning documents were photographed and captured to analyze their traditional management system.

The first university where this researcher conducted interviews was the UOZ. The UOZ has three libraries, for each library this researcher interviewed their librarians and employees. The time of each interview varied according to the free time each interviewees had. The second university was the UOD. This study has interviewed a number of librarians and employees to ensure how much they needed an electronic library.

However, the third university was NU where this study conducted the interviews in two different places due to venue problems. This study interviewed some of librarians and manager. Afterwards, by using SWOT analysis for the gained 
data from the interviews and observation, the outcome was for us. During these interviews we realized the strengths, weakness, opportunities and threats for the proposed system. The number of our strengths is (2), opportunities (2), weaknesses (11), threats (1) at each university.

Strengths: According to the answers of the data collected from (interviews and observations) Show that, this study is very important if there is an electronic system to manage an electronic library and if the system the capable of exchanging the information with other libraries inside the region or outside. Weaknesses: According to the data that were collected (interviews and observations). Based on these answers this study shows that there is an electronic system for university libraries, but not all systems are electronic. However, the employees at university libraries are facing many problems during their work because the current system has many problems such as time consuming for classification and searching for books. However, it does not serve the students and employees well because the current system allows the student and staff to search in desktop system in library and the system just for searching. So the current system cannot work regularly and effectively as books are constantly added, therefore, library needs a lot of time and effort and costs. However, the staff needs more time to sort and check books. In addition, the current system is not online. The students, staff and employees should borrow books just in library and during working hours. However, the employees cannot inform the students, staff and employees about the returning date of books. Therefore, the employees at libraries need online electronic system to solve all these problems.

Opportunities: Also, according to the data collected (interviews and observations) from UoZ, UoD and NU. Based on these answers this study shows that there is an electronic system in library, but it's not online. The current system will not be well with the extension of the library.

Threats: Also, according to the data collected from (interviews and observations) for UoZ, UoD and NU. The result shows that the staff does not have enough experience to use the computers well.

Depending on these answers, this study determined the Strengths Opportunities, Weakness and Threats of both, current and proposed system.

\section{SYSTEM REQUIERMENTS}

There are a number of requirements per project on various platforms regarding the proposed solution. In order to show the full description of needs of a system the requirements have been divided into the following categories:

- Functional requirements

- Non-functional requirements

- Software and Hardware Requirements.

\subsection{Functional Requirements}

Functional requirements stand for the action of the system which is done. These include a set of features that must satisfy the targets. The researcher's aims are to present an online library system for UOZ. Therefore, the system targets librarian and borrowers (including students, employees, academic staff, and public). For each of librarian and borrowers a set of features are required to satisfy the needs of the current system. These features had been determined through the author remark and interviews.

The functional requirements include:

$\checkmark$ Online users registration

$\checkmark$ Search and download

$\checkmark$ Tracking borrowed items

$\checkmark$ Ability to add material and news to the libraries

$\checkmark \quad$ Managing fines, reports, and borrowing records $\checkmark \quad$ Ability to add faculty libraries

$\checkmark$ Grant users to manage system tasks

$\checkmark \quad$ User profiles

Based on the functional requirements, a set of modules have been shaped which will be discussed in the following sections.

\subsection{Non-Functional Requirements}

Non-functional requirements are a number of features that could be used to measure the performance of the functionality in a system. Moreover, such requirements examine how the system functionality must be run since the proposed system is a web based one. This will lead to the following most significant features:

- User Friendly interface: The web site interface must be friendly to the users as much as possible. The better interface could be achieved by suitable graphical outcome and clear text. - Operative Links: The links are essential for a website as they have to redirect the user to the correct locations; for example, clicking on a book should lead the user to the main page of that book's borrowing report.

- Usability: The system should provide people with different computer usage experiences to use the system. It should be easy and friendly to use.

- Accessibility: Easy and remote access to information is required for multi users.

- Extensibility: The system should allow adding more functionality without complexity.

- Interoperability: The system must provide data and information in forms that can be operated by other systems. These may be implemented through a set of web services.

- Maintainability: Suitable control panel for each unit or page is required to easily maintain the contents.

- Reliability: Since multi users will work on multi units, the reliable completion of actions must be considered. Thus, each action must end within the correct results.

- Response time: The speed of operations is an important issue in the system. This is because the book borrowing need transaction and returning requires precise timing scheduling.

- Scalability: The system has to be flexible with any change in its size no matter to what extent those impacts could be.

- Security: The system must be secured so that unauthorized accesses are not allowed and the information exchanged should be secured as well.

\subsection{Software and Hardware Requirements}

The developing of a web service requires a number of features that include the following hardware and software tools. These are the very basic necessities of a website which is supposed to share data among its clients.

- Editors of programming languages.

- Hypertext Markup Language (HTML).

- $\quad$ Personal Home Page (PHP).

- JavaScript including (Ajax, and jQuery).

- MySQL database.

- A set of Web browsers for example Google Chrome, Mozilla Firefox, and etc.

- A computing device.

- Web and database server.

\section{PROPOSED SYSTEM DESIGN}

This section illustrates how the design of the system has been achieved. The ways of data collecting is shown in some lines of this part. The division, parts and accessibilities are being discussed along with the other methods in this part of research. 


\subsection{System Structure}

The design system structure it is a web-based online system which consists of three main parts. The first part is the clients, which include the students, staff and admen. The second part is the web services, which involves the interfaces and web application. The third part is the server, which consists of database, backup and recovery.

That provides service for its clients. The web service deals with the request from registered user to let them borrow a selective range of books. The system also tackle the issue of late returning by setting and managing a penalty fee which is applied when an item is late. The structure of the developed system is based on those factors.

Clients in OLMS can be divided into four levels of authorization. Clearly, each web service system is based on a rule scheme for its users. All types of users are included in the system structure and are dealing with the parts of the web service.

The users in LMS from high to low level are:

- Administrator

- Co_Admin (Cooperative Admin)

- Borrowers (registered user)

- Anonymous (unregistered user)

Every client in the four categories has a unique identification, authentication and a special authorization. These specifications can determine the level of the clients.

For any accountable web service there should be a way to distinguish users' privileges. A login system will help the server to create an environment for the selected user. In our developed structure, there is a login gate which lets registered user to enter the system with a new level of authority.

\section{- Administrator}

The main administrator is responsible for a number of processes which have been described in Figure (1).

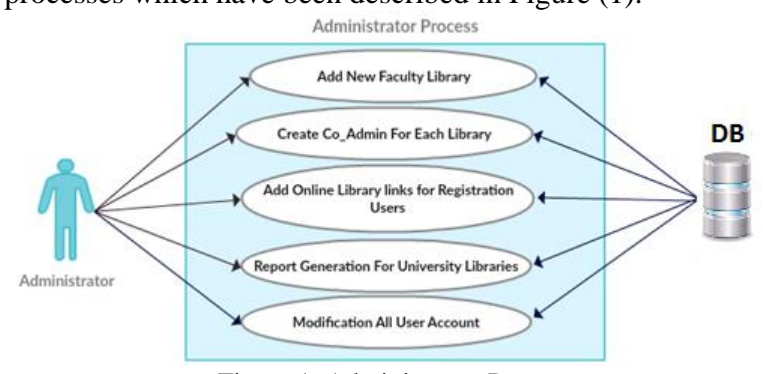

Figure 1. Administrator Process

- Co_Admin

Co_Admin is in charge of selecting a number of processes which are shown in Figure (2).

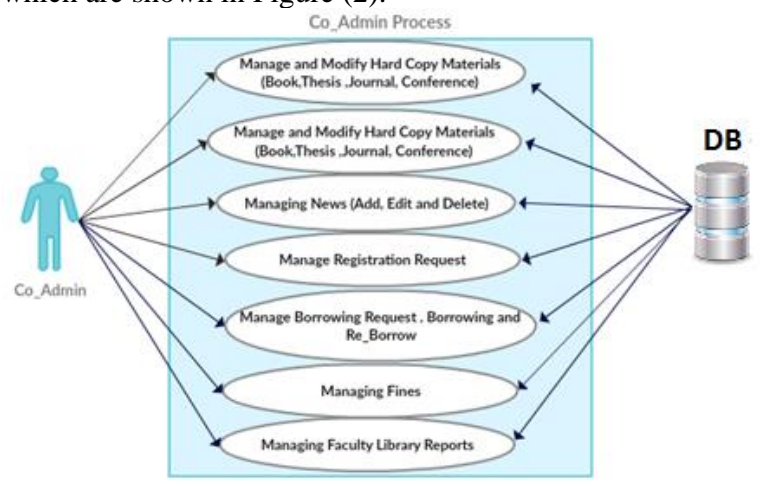

Figure 2. Co_Adminprocesses

- $\quad$ Borrowers (Registered Users)

The user has been given the abilities to do a list of actions and processes which are listed in Figure (3).

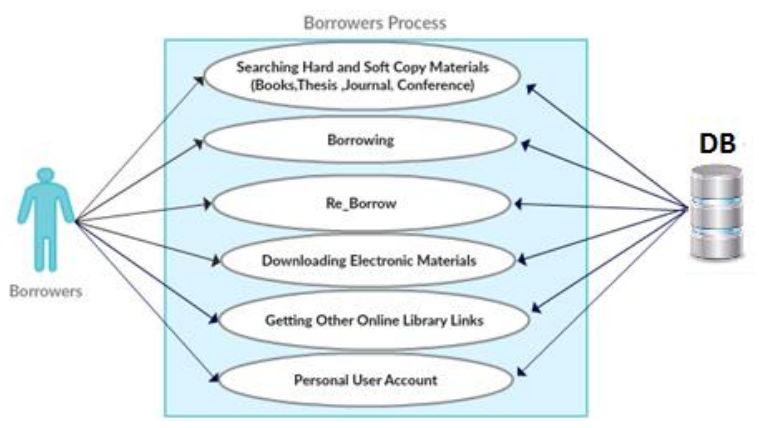

Figure 3. Borrower's processes

- $\quad$ Anonymous(Unregistered Users)

The unregistered user can use several web services as shown in Figure (4).

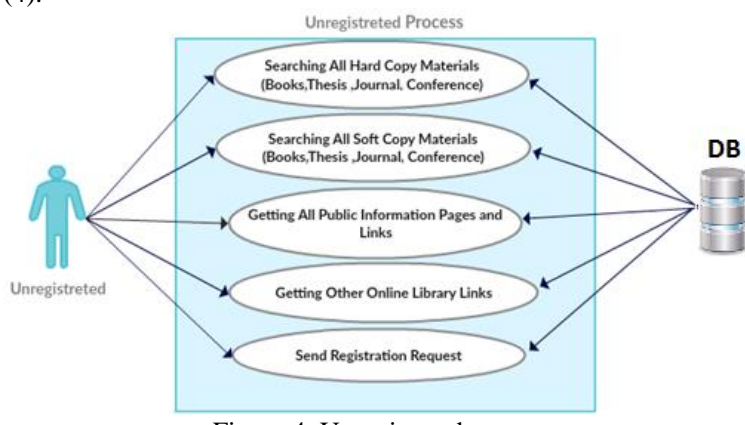

Figure 4. Unregistered processes

\subsection{System Modules}

The modules of this system have been designed based on the aspects and requirements of the web service. As it has been covered in previous sections regarding the interviews and observations, the modules of the proposed system have been selected. Generally, modules in the current system can be viewed in two categories:

According to the requirement of the interviews and observations, the OLMS have two categories of modules. The first category concerns the registered users and the second category concerns the unregistered users.

a. Registered User Modules.

b. Unregistered User Modules.

According to the users' authority there are a number of modules distributed among them. In this section those modules are discussed briefly along with their relationships with other parts of the system. The authority of unregistered user modules is available for registered users.

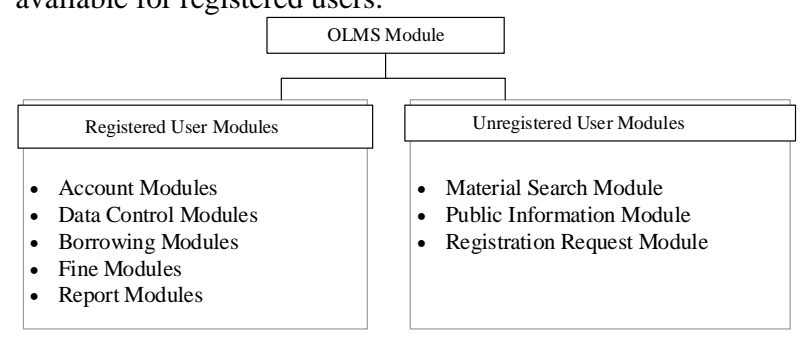

Figure 5. OLMS module categories

a. Registered User Modules

Registered User Modules contain several modules, they are:

- Account Modules

This module can be accessed only by system administrator. It provides the ability of adding, editing and removing libraries and their manager accounts (Co_Admin). The Co_Admin users have partial access to the library system where each one will be associated with a specified faculty. In addition, through this module the Administrator can combine two faculties or more in a single library and separate them any time to a set of libraries. Every faculty has its own special Co_Admin with 
unique account. Also, the separate libraries of the faculties can be accessed by one Co_Admin. Although, separated library might physically be available at the same place, their data are distinct. Therefore, whenever a nested library is ready to be an independent unit there is no need to manually separate their books. This operation can be done by the administrator within the system separation service. In addition to these abilities, the administrator has the power to modify his/her account's profile. All members (users) of the systems have the capability of viewing and editing their own profile. The member can view the (name of the faculty, department, work, email, phone number, name, table of sending request, table of borrowing and fines, table of borrowing history). Also, the members can edit (phone number and email).Finally, the members can also reborrow and cancel any request which is provided within personal account page.

\section{- Data Control Modules}

The administrator is responsible for all activities in the database which is the main key of this system that carries entire information about the developed service. The most important operation of the administrator in the database is backup and recovery. Backup will be done every period of time, while recovery will be done when needed or when a disaster happens. Co_Admin is the manager of the faculty library. Whenever a new item, such as a book, journal, conference, thesis or a workshop is scheduled to be held in the faculty, the Co_Admins are supposed to add that information to the web blog of the proposed system. In addition, whenever a new item is entered in the library system, the related department will be informed by a message. This, also, is the task of the Co_Admin who will be able to alert other members as well as departments. Undoubtedly, downloads are provided for electronic materials only for registered users. The system will show if the downloadb. of any item is possible. The online viewing of items will be also available for users to check if they require having a version of this material or not.

\section{- Borrowing Modules}

Borrowing basically a request from a user which is produced publicly and it will end up on the terminal of a Co_Admin. For searching materials there is no difference between types of users. The main difference between a registered member and unregistered members is noticed when borrowing is applied. The search will show the number of copies of each material being available in the actual library. If there is no accessible volumes in the search result, the closest ones to be returned will be shown to the user along with their returning expectation date. This aspect of letting material to be held by a member of faculty is given to the Co_Admin. The authorized member is allowed to rent a book for a limited period of time. Thesis, journals and conference are not borrowable due to library regulation. However, occasionally coalmines would lose the power to accept a request when the user has reached the borrowing item number limit. Therefore, the request will reject automatically and it will be shown on the terminal of the user. A report is available to be generated from the borrowing information to the console. All members are provided with the full renewing service for once per borrowing. The system will not let users re-borrow the material for second time. The reborrowing service is limited, and if the user fails to re-borrow before the time is exceeded, re-borrowing service will disappear. In addition to the limit of the mentioned service, renewing will not be available if the book has no other copies and there were external requests upon borrowing that single item. When the booking of an item is overdue, the fines are applied to the person with the book.

\section{- $\quad$ Fine Modules}

One of ways to organize the library management system is to trigger penalty fees for members that will not respect the time of borrowing. For this case, the member is fined with an amount of money which has to be paid to the Co_Admin. Therefore, the Co_Admin is supposed to monitor those fees and profile them in order to follow up each member's registered fines. Currently, due to poor banking system there is no available way for users to pay online; therefore, the Co_Admin will receive the fee by cash and it should be returned to the library.

\section{Report Modules}

Report producing is one of the key instructions which allow management members to monitor the follow of the system. With static reports library head members will observe the electrical and physical gates of the library system. There are a number of reports which administrator could generate. The main one is a complete static report on the number of materials (books, thesis, journals and conferences) which exist in the database for every faculty. In addition, there is a report exclusively for fees and fines of each faculty. Also the administrator can report the number of borrowing books and gives the sequence of the top five books borrowed in all faculties library. Moreover, the number of read thesis could be printed as a report for perceiving the popularity of each individual item in every faculty. Finally a report that declared the top five users borrowing books more than other users. Co_Admin will produce a static report at faculty level that he is in charge of about the number of materials (books, thesis, journals, and conference) and the number of borrowings and fines. Co_Admin will produce a log on complete data of the library. It includes all information which is not usable for current or future acts. However, they are kept as archive entities in case of need. For instance, whenever a user refuses to pay fines, these archived data will come in use.

\section{Unregistered User Modules}

Unregistered user modules contain several modules which are:

\section{- Material Search Module}

The search is open to public, and everyone is able to seek a book, thesis, journal or any other material. However, for downloading a soft copy, the user needs to be registered. This will apply copyright and conditions for the faculty which will be more secure for its members. For seeing more details of any particular item, the user can do it without being an official member. There is absolutely no difference in the case of filtering a search result for registered and unregistered users. There are two types of search in the system: category search and electronic search. Both searches are completely separate and have their independent filtering services. In each search result, the borrowing and downloading mechanisms are available if the user is registered. However, for unregistered users this option has been hidden out

\section{- Public Information Module}

Visiting the news page will not require a registration credential; therefore, news is basically the same for both types of users. However, the unregistered ones are not allowed to find the links which have been created by the administrator. Anonymous users are allowed to visit general interest pages of the system including contacting pages and (about us) blog. The home page information is also visible for all public visitors while borrowing the Web Pages. This information is essential for most of them. The info sections are open for any unregistered user who can see the website. Guiding visitors is one of the main functions of most of the servicing websites. Therefore, help and support pages have been designed for public visitors.

\section{- Registration Request Module}

The public is allowed to send the system a registration request for being a member of the authorized league. The user would need an ID_code for sending it to the Co_Admin of the faculty. 
Afterwards, if the request of that user is being approved, it means the user is now registered with the system. Meanwhile, the system will create an account for the newly registered member. This account is protected by identification and authentication which lets the user to enter the system as an authorized member. A member of library as a Co_Admin will have to deal with new registration requests. Registration requests will directly go to the request panel of the online web service. Depending on the faculty the Co_Admins will be able to accept or decline a registration application. Co_Admin are allowed to refuse a request considering the fact that the user is not a member of faculty. Members of faculty including students, academic staff and non-academic staff will keep an ID_code to be known in the system of library. Regarding this ID_codes, Co_Adminh as an easier task to determine whether to approve or reject an entreaty. In case of accepting or rejecting a request, the sender will receive the automatic email notification besides the auto SMS.

\subsection{System Interfaces}

The Online Library Management System's Web-Page can be opened by this URL: (http://library.uoz.edu.krd/) in University of Zakho's main page as shown in figure (8).

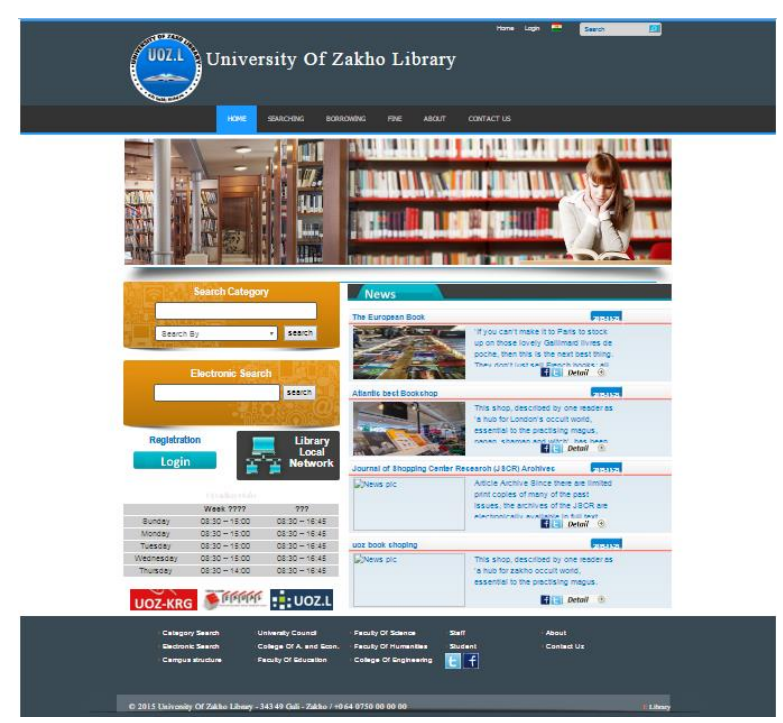

Figure 6. Graphical user interface of OLMS

The implemented website of online library management system has a number of pages. These pages need a basic knowledge from the users to use it. According to that a complete web service map is inserted for the users. So, the site map of OLMS consists of three levels as shown in Figure (8).

a. Level one: (index/home page), is concerned with the main structure of the electronic library system available for anyone.

b. Level two: is concerned with the level of the users.

c. Level three: is concerned with the functions or tasks of each section in the electronic library system.

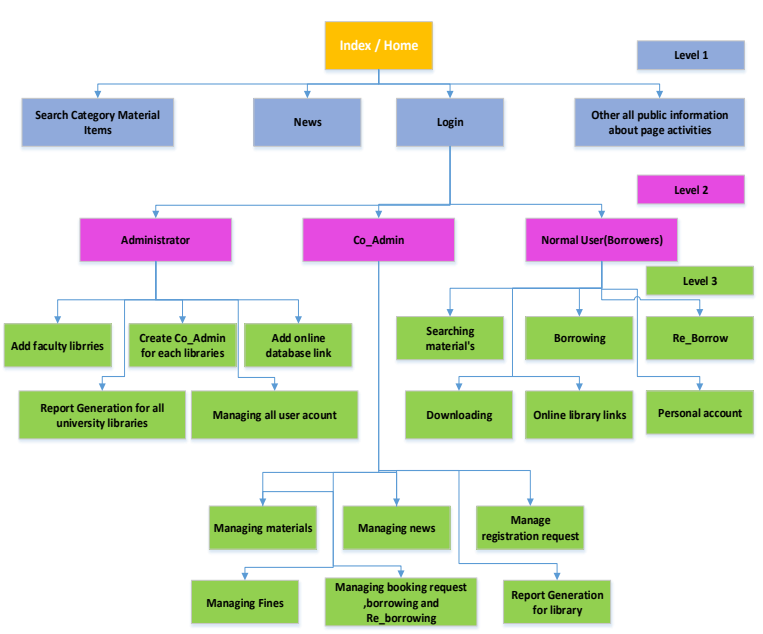

Figure 7. OLMS's site map

\section{SYSTEM IMPLIMENTATION}

The library management system has been implemented on the website of University of Zakho. The system offers services for all members of the university. The total number inserted items in the library database shown in Table (1).

Table 1 . The total number of inserted items in library database

\begin{tabular}{|c|c|c|}
\hline No & Item & Count \\
\hline 1 & Books & 15504 \\
\hline 2 & Electronic Books & 950 \\
\hline 3 & Thesis & 1020 \\
\hline 4 & Electronic Thesis & 120 \\
\hline 5 & Journal & 119 \\
\hline 6 & Conference & 4 \\
\hline
\end{tabular}

\section{RESULTS OF SYSTEM USABILITY TESTING}

The System Usability Scale (SUS) was developed by John Brooke and was first published in 1996. SUS is a tool that can be used to collect data from empirical user testing. Brooke himself describes that "The System Usability Scale (SUS) is a simple; ten item scale giving a global view of subjective assessments of usability". In his 1996 paper that introduces the now widely used SUS-scale, Brooke starts by defining usability by the ISO 9241-11 standard (usability as a combination of effectiveness, efficiency and satisfaction) (Joonas K, 2013). The online testing system was performed during a period of $(90$ days) starting from $(6 / 12 / 2015)$ to $(6 / 3 / 2016)$ in University of Zakho by a number of university members such as (staff of library, students and some academic-staff). Also during this online test the researcher run two training courses for the staff of all universities libraries. The SUS questionnaires are used in this paper. The content of this questionnaire consisted of ten questions, five of them are positive (odd number) while five others are negative (even number). This test was done in University of Zakho with the same people who participated in the test first time. The SUS testing period was (5 days), from $(3 / 4 / 2016)$ to $(7 / 4 / 2016)$. The main purpose of this questionnaire is to evaluate the usability of OLMS paying attention to effectiveness, efficiency and satisfaction from the system users. The results of the test are shown in Table (2). 
Table 2. SUS Score by the participants $(\mathrm{N}=26)$

\begin{tabular}{|l|l|l|l|}
\hline Participant & SUS score & Participant & SUS score \\
\hline User1 & $85 \%$ & User14 & $85 \%$ \\
\hline User2 & $60 \%$ & User15 & $77.50 \%$ \\
\hline User3 & $77.50 \%$ & User16 & $85 \%$ \\
\hline User4 & $87.50 \%$ & User17 & $60 \%$ \\
\hline User5 & $72.50 \%$ & User18 & $57.50 \%$ \\
\hline User6 & $100 \%$ & User19 & $82.50 \%$ \\
\hline User7 & $55 \%$ & User20 & $55 \%$ \\
\hline User8 & $87.50 \%$ & User 21 & $55 \%$ \\
\hline User9 & $55 \%$ & User 22 & $95 \%$ \\
\hline User10 & $62 \%$ & User 23 & $85 \%$ \\
\hline User11 & $100 \%$ & User 24 & $55 \%$ \\
\hline User12 & $95 \%$ & User 25 & $95 \%$ \\
\hline User13 & $77.50 \%$ & User 26 & $77.50 \%$ \\
\hline SUS Total Score & $76.15 \%$ & \\
\hline
\end{tabular}

In the current usability test, 26 users participated in testing of the system. The minimum SUS score is $55 \%$ while the maximum score is $100 \%$. Therefore, the total score of SUS is $76.15 \%$ indicating that (OLMS) is generally acceptable in accordance with the rules of the SUS tools as $70 \%$ acceptable ratio.

The survey results show that the overall satisfaction of OLMS is high. Again, depending on the results some important points can be concluded. The score (3.61) for (Q1) it means that users find this system easy to use frequently. Furthermore, the score (2.807) for (Q2) means that the users faced some complexity; this could be a low score and a good result. Moreover, the score is (3.076) for (Q3) means that the users find this system useful. However, the (Q4) score which is (2) means that the users would need assistance to be able to use this website. The score (3.807) of (Q5) means that the users found that various functions in this system were well integrated. The score (3.307) of (Q6) means that the participant found the system inconsistent. Also, the score (3.384) of (Q7) means that the users find this system a quickly learnable to be used by people. According to $(\mathrm{Q} 8)$ the score (3.115) means that the system is very cumbersome to use. The score of (Q9) which is (3.5) means that the users felt very confident using OLMS. This is a high score and a good result. The last question is (Q10) that had a score of (1.884). It means the users need to learn many things before they can use this system as shown in figure (9).

\section{Mean "SUS" Answer Scores by Question}

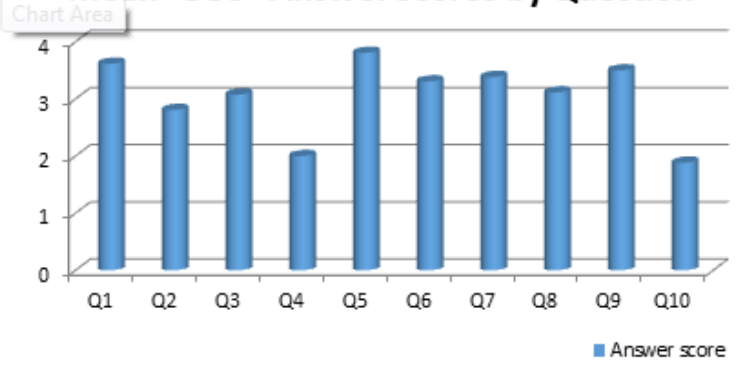

Figure 8. Mean survey result $(\mathrm{N}=26)$

\section{CONCLUSION}

The SWOT analysis shows that, from the weaknesses side of the traditional system is that there is no digital system. Also, from the strength side shows that the university employees need an electronic library management system. Also, the testing results on the design system the users indicate that the overall satisfaction of the current system was (76\%) successful based on their answers of the SUS questionnaire. During the test, some problems appeared. These problems were mainly related to the weak of the internet and lack experience by users. As well as the implementation part results show that the current system is better than the formers systems in terms of SMS and Email facilities. This lets the users know about every update happen. Also by using the current system the administrator can easily separate the content of many libraries in case they desire to be independent libraries. This process was very difficult to be done in the formers systems. The results also show that the current system is more efficient than the formers ones with respect to the borrowing process. This process can be done online by the authorized users anytime and anywhere. The results stated as well that the current system is more efficient than the former ones when it comes to producing reports. This process can be carried out through one click anytime and anywhere by the administrator and Co_Admins. The users of the current library system proved that the use of the system is easy and does not need any knowledge concerning any programming languages. However, this doesn't mean they don't need any skills in using the computer. As compared to other previous systems, the current system has lower chances of errors in terms of borrowing and fine processes.

\section{REFERENCES}

Al-Juboori, A. F. M. A. (2014). Design and Implementation of an ELibrary Search System. International Journal of Innovation and Applied Studies, 7(4), 1321.

Aruleba, K. D., Akomolafe, D. T., \& Afeni, B. (2016). A Full Text Retrieval System in a Digital Library Environment. Intelligent Information Management, 8(01), 1.

Chiagunye, \& Nwachukwu. (2015). Designing a Web Based Digital Library Management System for Institutions and Colleges. International Journal of Innovative Science, Engineering \& Technology, 2(3).

David. (2012). Qualitative Methods Overview. British Business School QM-A2-Engb, Heriot-Watt University (1022).

Jo, M. (2011). Qualitative methods overview.

Joonas, K. (2013). Usability testing throughout the application lifecycle.

McCann, T. V., \& Clark, E. (2005). Using unstructured interviews with participants who have schizophrenia: Unstructured interviews offer a potential source of rich data in nursing research. In this paper, Terence McCann and Eileen Clark examine the challenges presented when unstructured interviews are used with participants who have schizophrenia. They consider unstructured interviewing in the context of an Australian study of how community mental health nurses promote wellness with clients who are experiencing an early episode of schizophrenia. Nurse researcher, 13(1), 7-18.

Morium, M. (2008). Open source library management system. BRAC University.

Neelakandan, B., Duraisekar, S., Balasubramani, R., \& Ragavan, S. S. (2010). Implementation of automated library management system in the School of Chemistry Bharathidasan University using Koha open source software. International Journal of Applied Engineering Research, 1(2), 149. 